\title{
DESIGN OF BIAXIAL TENSILE CRUCIFORM SPECIMEN BASED ON SIMULATION OPTIMIZATION
}

\author{
Rui Xiao ${ }^{a}$, Xiaoxing $\mathrm{Li}^{\mathrm{b}}$, Lihui Lang ${ }^{\mathrm{c}}$, Yangkai Chen ${ }^{\mathrm{d}}$, Yulong $\mathrm{Ge}^{\mathrm{e}}$ \\ (School of Mechanical Engineering and Automation, Beijing University of Aeronautics and \\ Astronautics, Bei jing 100191, China) \\ axiaoruidiablo@163.com, ${ }^{\mathrm{b}}$ li.xiaoxing@buaa.edu.cn, ${ }^{\mathrm{c}} 88229015 @ q q . c o m$, \\ dcykangel@126.com, enoahge88@163.com
}

Keywords: Biaxial tensile testing, Cruciform specimen, Finite element method, plastic deformation, Thickness of central area, Fillet radius

\begin{abstract}
In this paper, the design methods of cruciform specimen of biaxial tensile testing are summarized. In order to study the stress and strain distribution of sheet metal under plastic deformation stage, the specimen shape is designed according to the principles of stress-strain distribution homogeneous in the center area and stress concentrations in the arms. Based on the sample size recommended by the biaxial tensile test international standard tensile properties and the mechanical properties of 45 steel, the simulation model was established. The influence and regularity of the parameters on the test results are calculated by the finite element method, and the optimization is carried out. Optimization results show that thickness of central area can be decreased moderately based on a half of the original thickness, and the best value should be controlled by $40 \%$ to $50 \%$; the outward fillet radius can be increased moderately based on the design of slot in arms and thickness reduction in the central area, and the radius value be controlled by $2-7 \%$ of specimen width.
\end{abstract}

\section{Introduction}

In recent years, sheet forming by plastic processing, especially for aerial and spacecraft alloys, are widely adopted. In an attempt to retrench design cost, the finite element method for calculating the deformation of sheet metal has become an almost obligatory step. The accuracy of these numerical simulations is contingent on the chosen constitutive model. Focusing on predicting the plastic behavior of metals, many investigations have been conducted by MTS or Gleeble thermo uniaxial tensile testing machines ${ }^{[1 ; 2]}$. However, it has been recognized that many structures are usually under multiaxial loading conditions in manufacture. Multiaxial stresses and strains cannot be detected by uniaxial data. Under same true strain state, on the basis of stress yield theories, certain distinctions exist between the stress obtained from uniaxial loading in a direction and those from multiaxial loading in the same direction. Therefore, biaxial tension testing describes mechanical properties of materials under multiple loading more precisely than uniaxial tensile testing, with the setups being close to actual physical scenarios.

Biaxial tension testing technique and early cruciform biaxial tension specimen was first proposed by Shiratori and Ikegami ${ }^{[3]}$. However, the area of arms is far less than that of center section, which lead the specimen arm to being fractured before the center section reach forming limit under normal stress in the test ${ }^{[4]}$. It is essential to increase the deformation in the center section as far as possible while designing according to specimen thickness so that there are more effective data of post yield point to fit stress-strain curves and constitutive model that is consistent with the actual material properties. With more research on biaxial tension technique, specimen design has been improving by leaps and bounds ${ }^{[5]}$. In 1992, Makinde designed the specimen on the basis of the arm slits and thinning in both sides of the central area to increase deformation in the test section ${ }^{[6]}$. The specimen recommended by biaxial tensile test ISO/CD16842 international standard issued in 2014 is designed by Japanese expert Kuwabara researching plastic behavior of carbon steel in 1998, but there is no processing to the central area ${ }^{[7]}$. This kind of specimen was widely used in researching on the 
constitutive mold and forming limit of materials in a very long time ${ }^{[8 ; 9]}$. Then M.Merklein proposed a design with strips and slots in arms and thinning in only one side of the central area based on the above studies ${ }^{[10]}$. In addition, Wu Xiang-dong and Lionel Leotoing also investigated thinned methods of center area in order to research on forming limit of metal sheet ${ }^{[11 ; 12]}$. But different from plastic, for the research on forming limit, it is unnecessary to consider the stress distribution in the test area. Therefore, it is lack of discussion on the shape and size of the specimen for the study on the plastic deformation of the metal sheet. With the change of the thickness and the fillet radius between arms of the specimen, the test results will be affected. It is in this context, in order to provide a theory and standard for the design of cruciform specimen, geometrical shape of the specimen was discussed and optimized by using the finite element simulation.

\section{Cruciform specimen design and geometry}

There are at least two principles of designing biaxial tension specimen ${ }^{[13]}$ :

1 , Stress-strain homogeneity within the center section so that we can calculate the stress with deviations as less as possible.

2, Yield has to occur in the test section and stress concentrations to avoid fracturing in arms.

Based on the above two points, three main methods can be seen as shown in Figure 1: cutting a circular groove at the corner area, which can avoid fracture while experiment; reducing thickness of the central section, which avoid stress concentration in arms, and thus can increase the deformation at the center; the strips and slots in arms reduce the effect of shear stress.

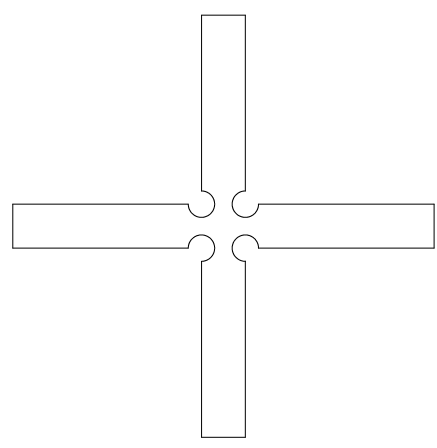

Cut type

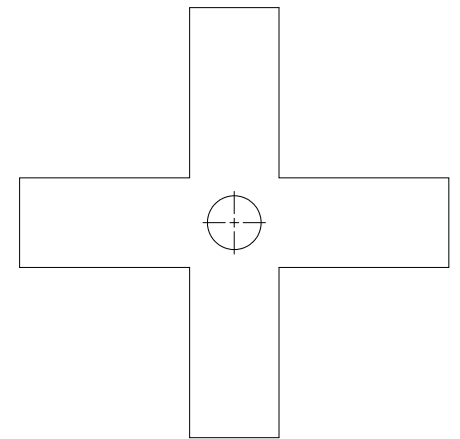

reduced section type

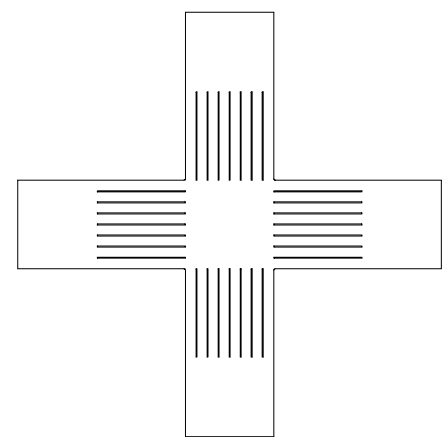

strip and slot type

Fig. 1. Geometry for cruciform type specimen.

The length and width of ISO/CD16842 international standard specimen with strips and slots is $240 \mathrm{~mm}$ and $50 \mathrm{~mm}$, respectively. The design for biaxial test has played an important role in the research on the stress near the yield. But the extension ratios of the center area are too low, therefore the center section of the specimen should be thinned down. There are two thinning methods: bilateral thinning and unilateral thinning. For the common thickness (2-3 $\mathrm{mm}$ ) specimens, it is very difficult to do bilateral thinning except by EDM which costs a lot. Therefore, in this paper, based on the standard length and thickness $(2 \mathrm{~mm})$ of ISO/CD16842 specimen is designed, unilaterally thinned, as shown in Fig. 2. Fillet radius $R$ and thickness of central area $H$, the key dimensions which may have great influence on distribution of forces, are discussed. 

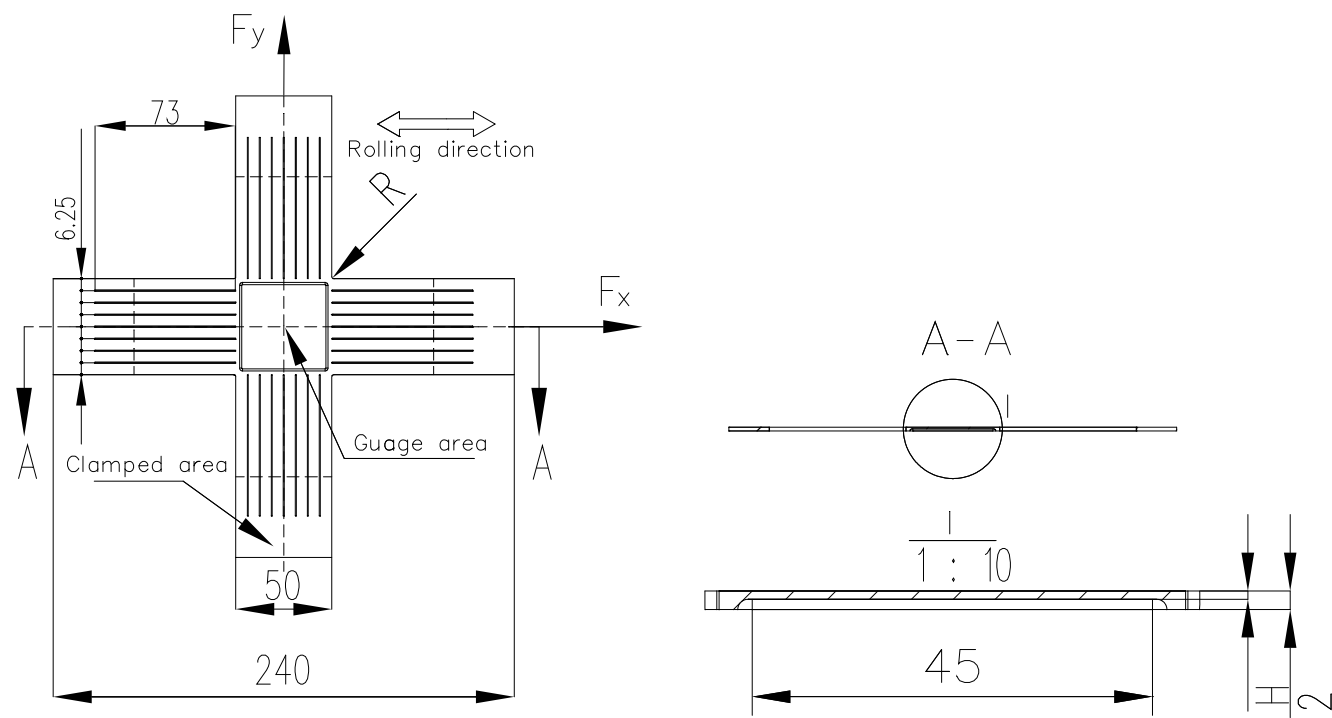

Fig. 2. Biaxial specimen geometry.

In biaxial tension technical field, finite element simulations of the cruciform specimen can be studied by comparing the influence of various geometrical parameters on stress and strain distribution to optimize the geometry. In order to simulate efficiency, a quarter of specimen model is established as shown in figure 3. Experimentally, true strain $\varepsilon_{x}$ and $\varepsilon_{y}$ were directly measured by digital image correlation. For calculating the stresses, taking exemplary $A S_{y}=A S_{y, 0}+A S_{y, 1}$ and $A S_{y, 0} \gg A S_{y, 1}$, which leads to engineering stress $\sigma_{y} \approx F y / A S y$. This assumption was taken considering non-reduced thickness section during the deformation. Fortunately, we can calculate, according to ISO 80000-1, the digit of true stress $\sigma_{y}{ }^{\prime}=\sigma_{y}\left(1+\varepsilon_{y}\right)$.

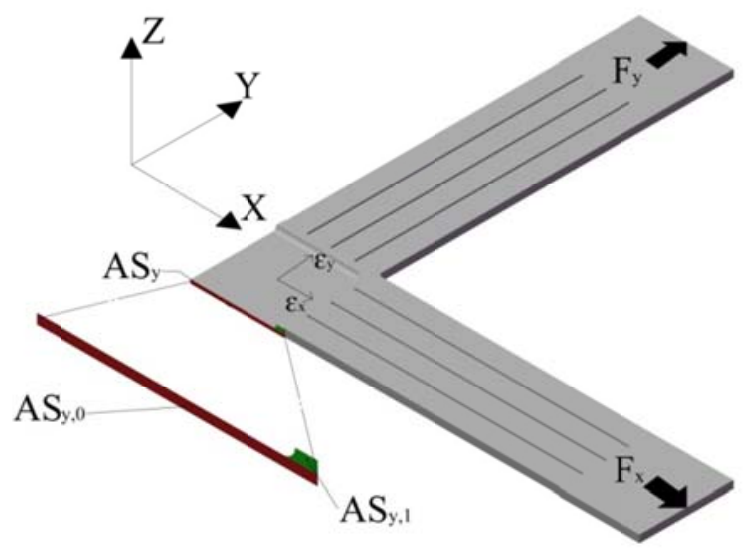

Fig. 3. Schematic representation of the experimental evaluation method.

Appropriate thinning has little effect on the mechanical properties of materials. The stress distribution become inhomogeneous, and strain and shear stress both increases which will lead to the fracture when the central region thickness decreases; conversely, strain decreases and rupture happens at arms prematurely, which fail to achieve the expected results when the thickness increases. In this paper we considered thickness reduction to below half of origin $(0.7 \mathrm{~mm}, 0.9 \mathrm{~mm})$, and for comparison, specimen of $1.1 \mathrm{~mm}$ thickness is also analyzed.

Here, two different strategies of the corner shape modifications of the central area are proposed: As shown in figure $4 \mathrm{~A}$, the convex corner radius $R_{A}$ is discussed; by reference to cut type design, the concave corner whose radius $R_{B}=2 \mathrm{~mm}, 3 \mathrm{~mm}$ and $5.5 \mathrm{~mm}$ when it reach the central area, is also tried to optimize the stress distribution. 


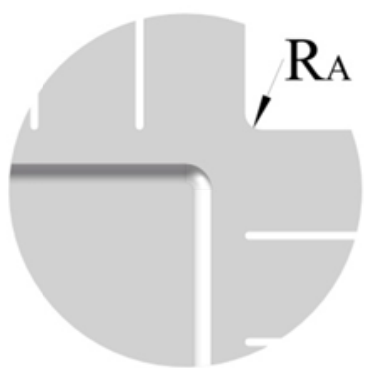

A

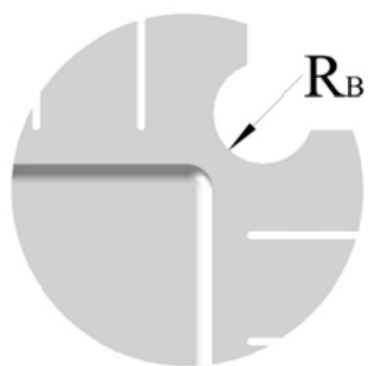

B

Fig. 4. Schematic representation of $R$.

ANSYS/LS-DYNA was used for the analysis. Because of unilateral thinning of specimen, all models are built up by eight-node linear brick elements (solid164) with edges of $1 \mathrm{~mm}$. Material curve is from uniaxial test of cold-rolled steel. Elastic modulus is $206 \mathrm{GPa}$, poisson ratio is 0.28 , yield strength is $245 \mathrm{MPa}$, tangent modulus is $5800 \mathrm{MPa}$. The displacements of direction $\mathrm{X}$ and $\mathrm{Y}$ are $15 \mathrm{~mm}$. Moreover, the simulation time is $0.1 \mathrm{~s}$ and time step is $1.6 \times 10^{-6} \mathrm{~s}$. The essential data of different model types are compared in Table 1.

Table 1 Model data for FE-simulation

\begin{tabular}{|c|c|c|c|c|c|c|c|c|}
\hline Fillet radius $(\mathrm{mm})$ & $R_{A}=1$ & $R_{A}=1$ & $R_{A}=1$ & $R_{A}=3$ & $R_{A}=4$ & $R_{B}=2$ & $R_{B}=3$ & $R_{B}=5.5$ \\
\hline$H(\mathrm{~mm})$ & 0.7 & 0.9 & 1.1 & 0.9 & 0.9 & 0.9 & 0.9 & 0.9 \\
\hline Elemetnts & 75916 & 76268 & 93860 & 76138 & 80602 & 77551 & 84378 & 73884 \\
\hline Nodes & 20929 & 20980 & 24440 & 20951 & 21853 & 21199 & 22536 & 20436 \\
\hline
\end{tabular}

\section{FE-simulation and influence of geometrical parameters}

When $R_{A}=1 \mathrm{~mm}$ and $H$ is from $0.7 \mathrm{~mm}$ to $0.9 \mathrm{~mm}$, specimen deformation and strain distribution are shown in the figure below. From mechanical strain diagram, it can be seen that the strain of center area increases with the increase of thickness $H$. By comparison of the Fig. 5A and 5B, the slot near the fillet shows a large deformation caused by shear stress. For the specimen of $H=1.1$ $\mathrm{mm}$, the shear stress is obviously reduced, but the deformation of the center region is obviously decreased. The common ground of the three designs is that the total mechanical strain near the fillet is the largest in the center region; thus from this region to the center point of specimen strain spreads and becomes low. Moreover, strain distribution becomes uniform with the increase of thickness.

Mechanical strain

Shear stress

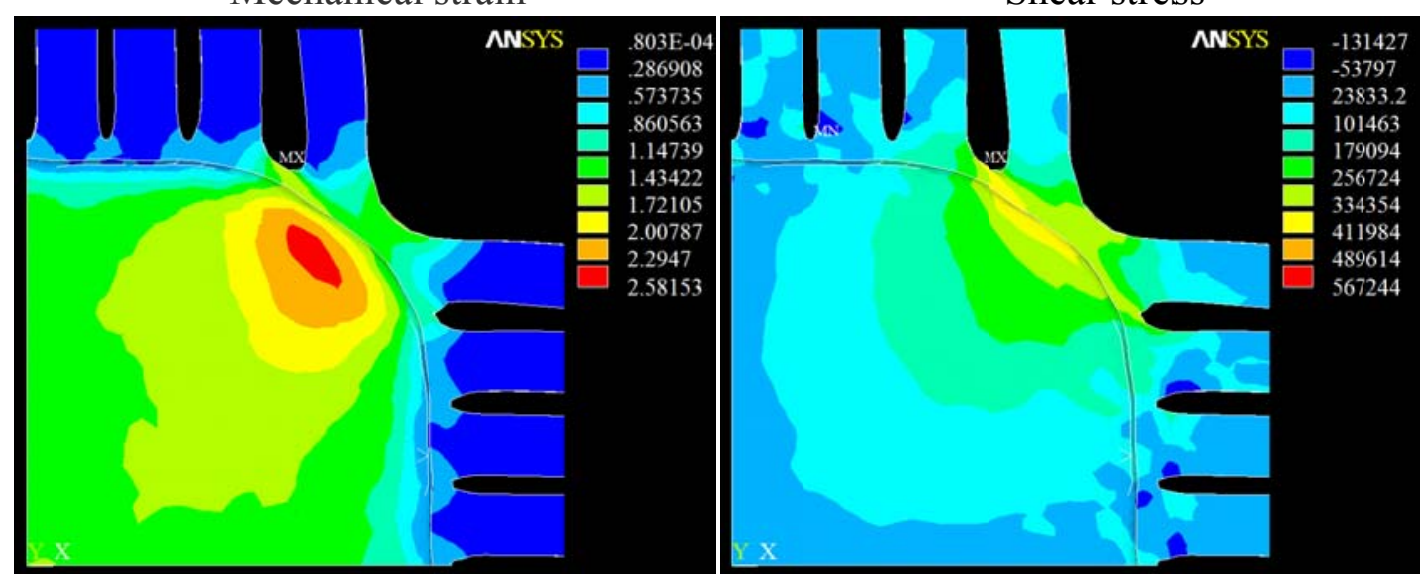

A $H=0.7 \mathrm{~mm} R_{A}=1 \mathrm{~mm}$ 


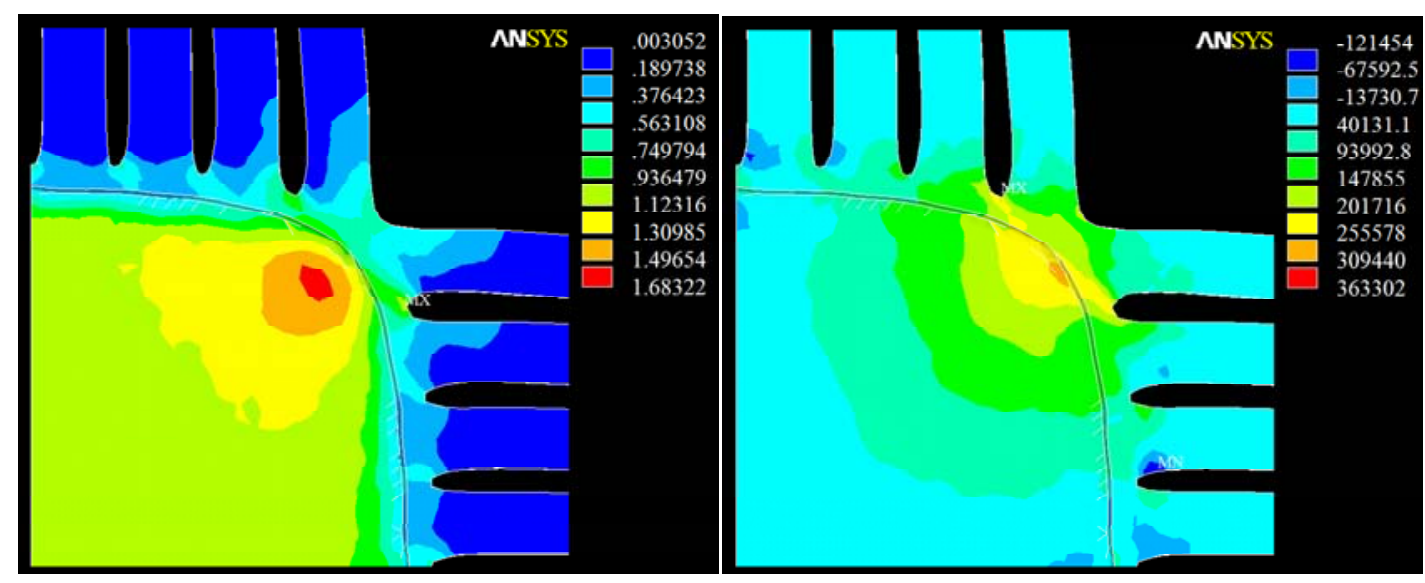

B $H=0.9 \mathrm{~mm} R_{A}=1 \mathrm{~mm}$

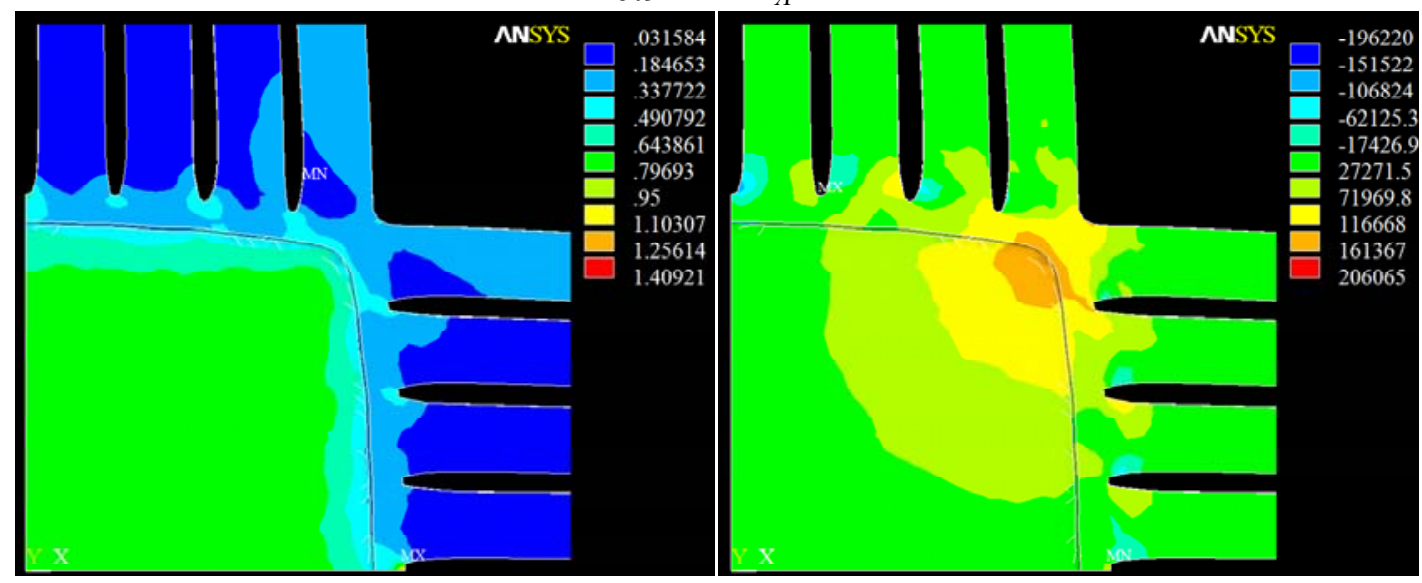

$\mathrm{C} H=1.1 \mathrm{~mm} R_{A}=1 \mathrm{~mm}$

Fig. 5. Mechanical strain and shear stress distributions for different thickness $H$.

From the angle of 45 degrees, 5 nodes in Fig. 6 are equally spaced by taking the center of the specimen as the origin and the Mises stress-time curve diagram is drawn to compare among three designs. Firstly, we can see the stress value is higher in the location farther away from the center point. When the geometry has an increase thickness in the central region of the specimen, stress gradually goes into a more stable state. Sencondly, Mises stress values of A area, which is at the center point, are close to these of B area; the stress gap become lager in C, D, E area, but the gap is getting smaller with the increase of thickness, which means stress distribution uniformity is better. Especially, when the thickness reaches $1.1 \mathrm{~mm}$, stress values in every area are very close.

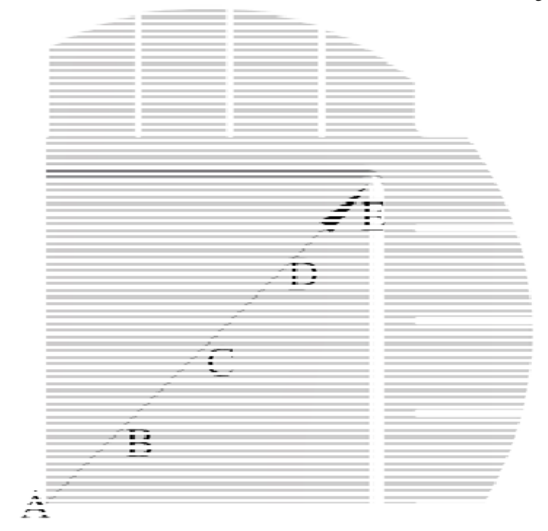

Fig. 6. Position of sample nodes. 


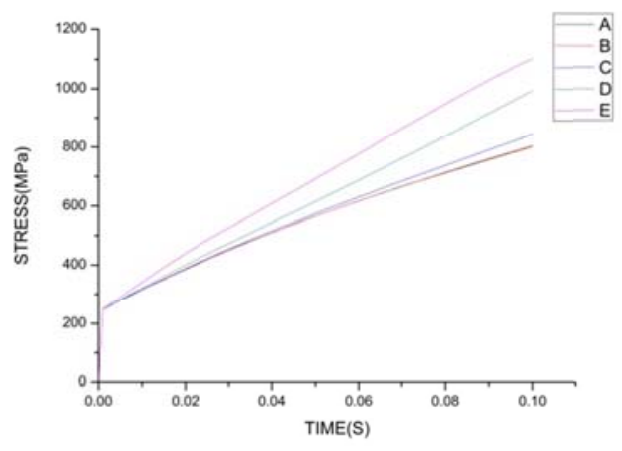

A $H=0.7 \mathrm{~mm} R_{A}=1 \mathrm{~mm}$

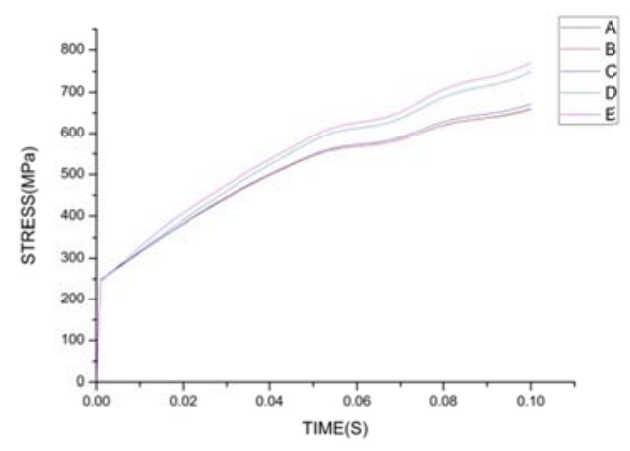

B $H=0.9 \mathrm{~mm} R_{A}=1 \mathrm{~mm}$

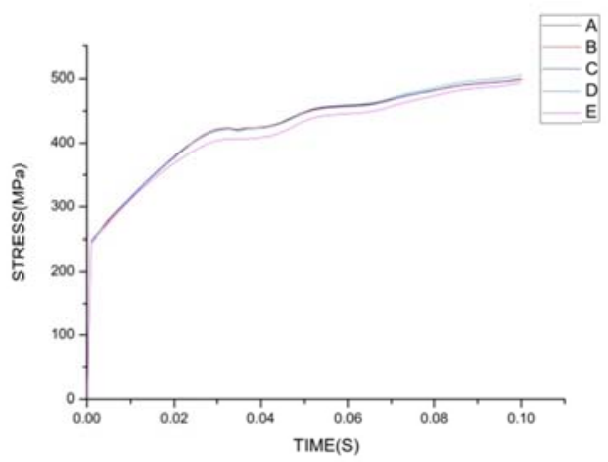

$\mathrm{C} H=1.1 \mathrm{~mm} R_{A}=1 \mathrm{~mm}$

Fig. 7. Mises stress-time curve for each point for different thickness $H$.

Fig. 8 is the total mechanical strain and shear strain cloud image of the concave design. The strain mainly concentrate in the fillet position caused by shear stress but not arm slots. With concave radius increasing, it also can be seen that stress distribution uniformity became worse while strain in the central area reduce. When concave radius increase to the central area, stress distribution completely lost their regularity. Here, it can be recognized that the method to take cut type into reduced section and strip and slot type is feasible.

Mechanical strain

Shear stress

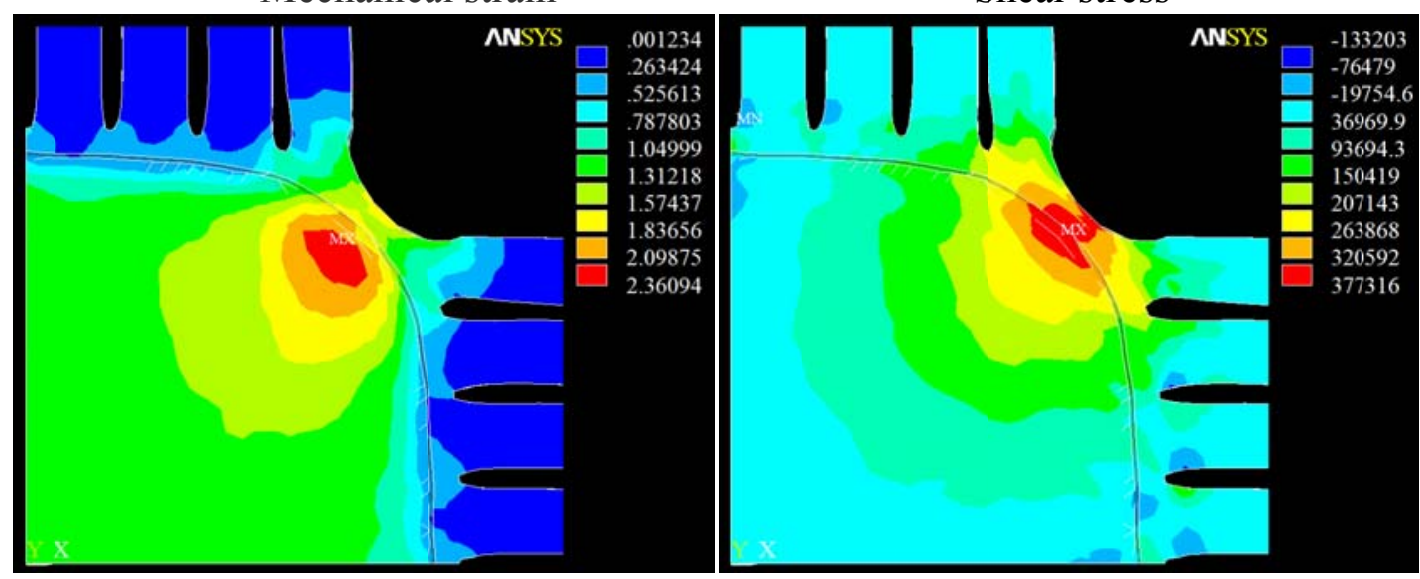

A $H=0.9 \mathrm{~mm} R_{B}=2 \mathrm{~mm}$ 


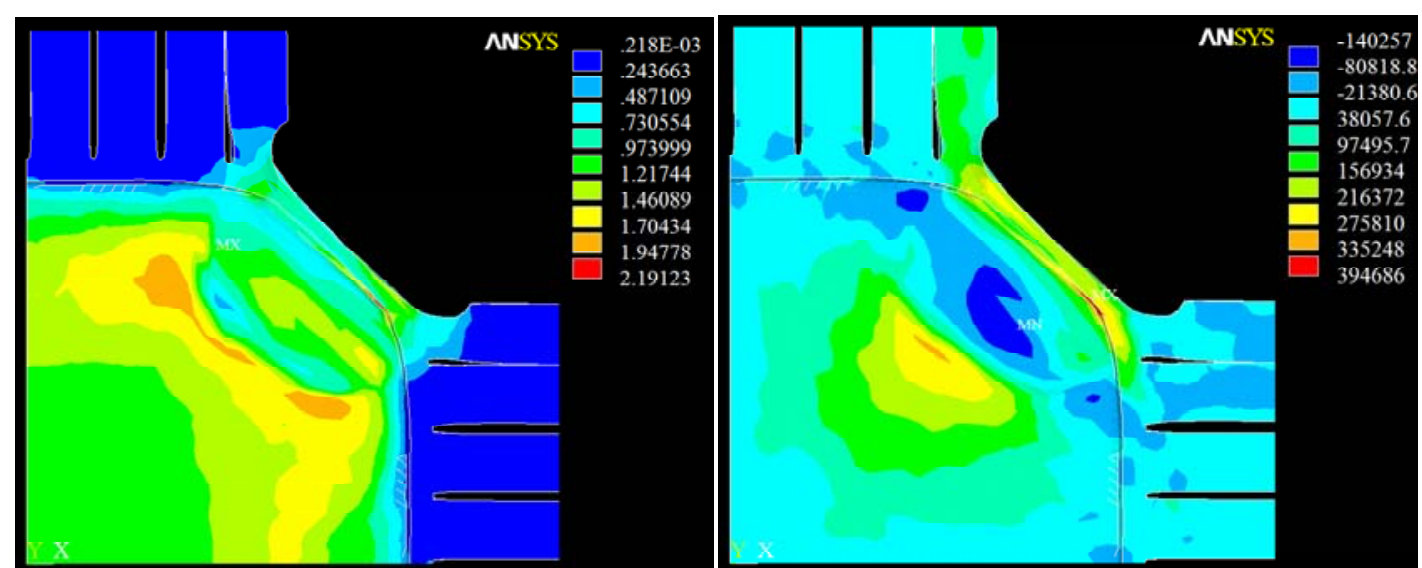

B $H=0.9 \mathrm{~mm} R_{B}=3 \mathrm{~mm}$

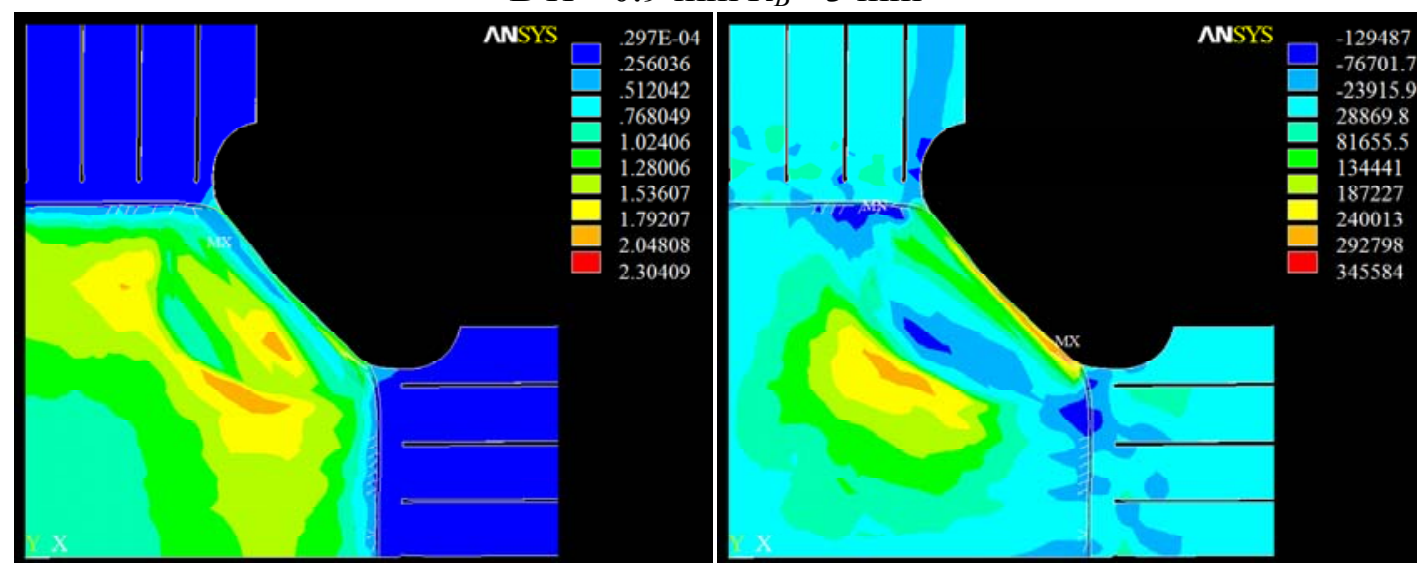

$\mathrm{C} H=0.9 \mathrm{~mm} R_{B}=5.5 \mathrm{~mm}$

Fig. 8. Mechanical strain and shear stress distributions for different $R_{B}$.

According to concave fillet design, in this paper shear stress and strain distribution is verified when fillet $R_{A}(H=0.9 \mathrm{~mm})$ increases outwards. Strain distribution uniformity is much better with $\mathrm{R}_{\mathrm{A}}$ of $1 \mathrm{~mm}$ up to $3 \mathrm{~mm}$ as it is shown in Fig. 9, which meets the requirements of the experiment. In this paper the maximum shear stress of each specimen is plotted in Fig. 11 which emphasis that the maximum shear stress value has been reduced although it is still being in the region of slot. And then, Mises stress declines and the maximum shear stress value changes little with $R_{A}$ up to $4 \mathrm{~mm}$, which illustrates that shear stress in the middle the slot will increase by expanding $R_{A}$, and the optimization effect is limited beyond this range. In comparison with stress-time curves of the graph $7 \mathrm{~B}$ and10A, stress value is so close that there is little change in strain in central area with the fillet enlarged so that we can conclude the reduction of shear stress leads strain distribution to being even.

Mechanical strain

Shear stress

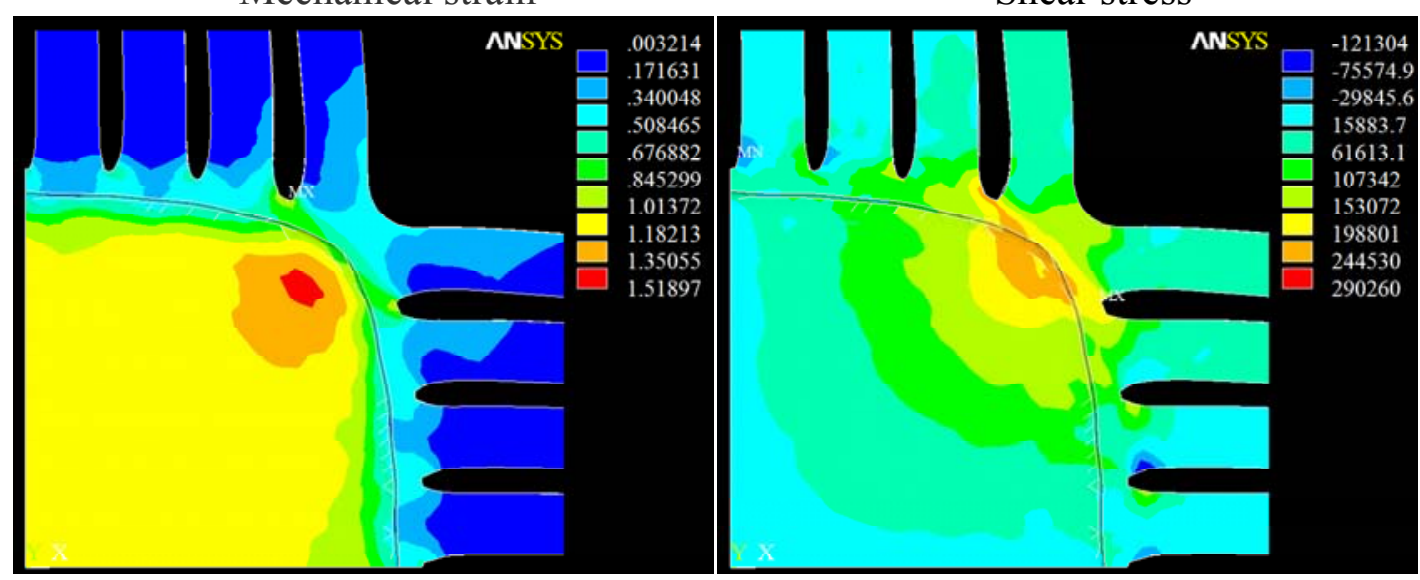

A $H=0.9 \mathrm{~mm} R_{A}=3 \mathrm{~mm}$ 


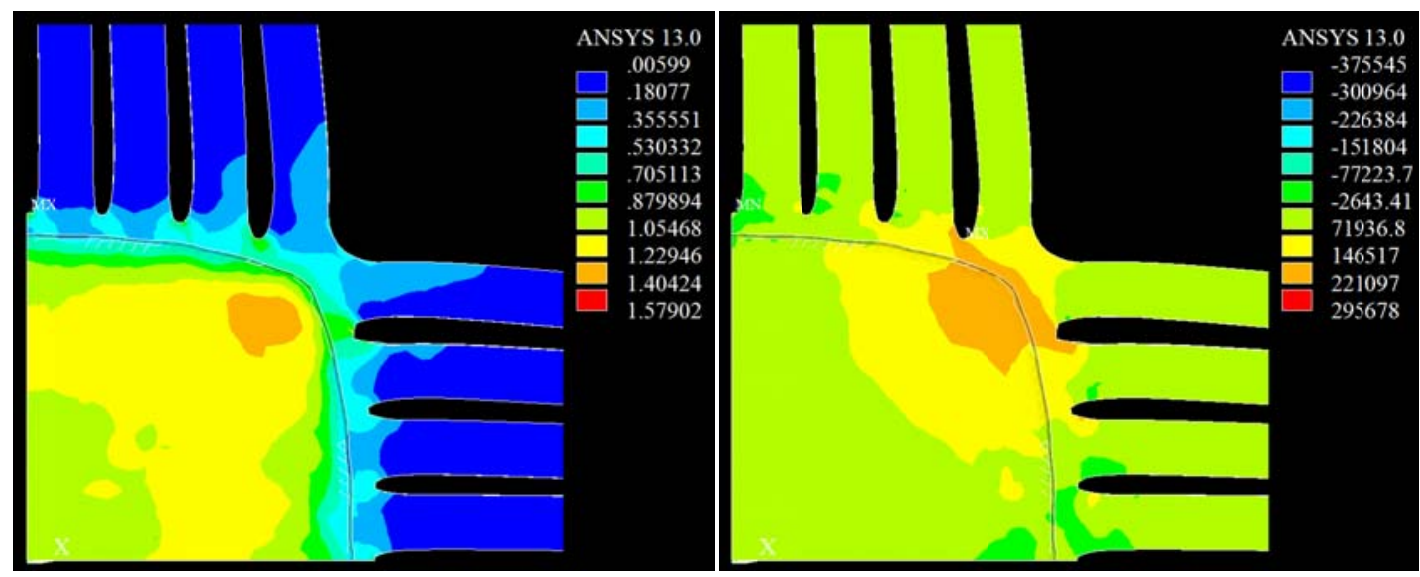

B $H=0.9 \mathrm{~mm} R_{A}=4 \mathrm{~mm}$

Fig. 9. Mechanical strain and shear stress distributions for different $R_{A}$

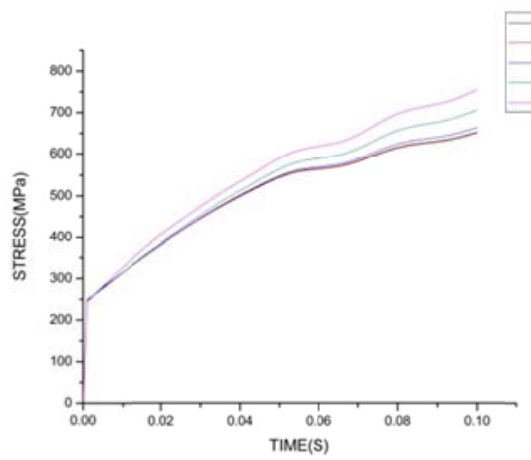

A $H=0.9 \mathrm{~mm} R_{A}=3 \mathrm{~mm}$
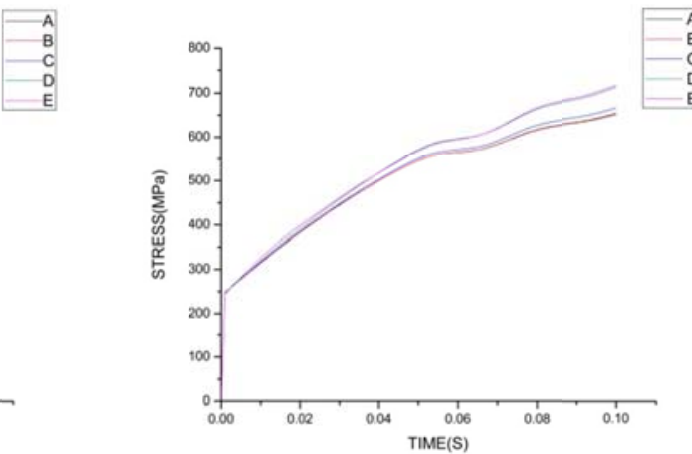

B $H=0.9 \mathrm{~mm} R_{A}=4 \mathrm{~mm}$

Fig. 10. Mises stress-time curves of each point for diffreent $R_{A}$.

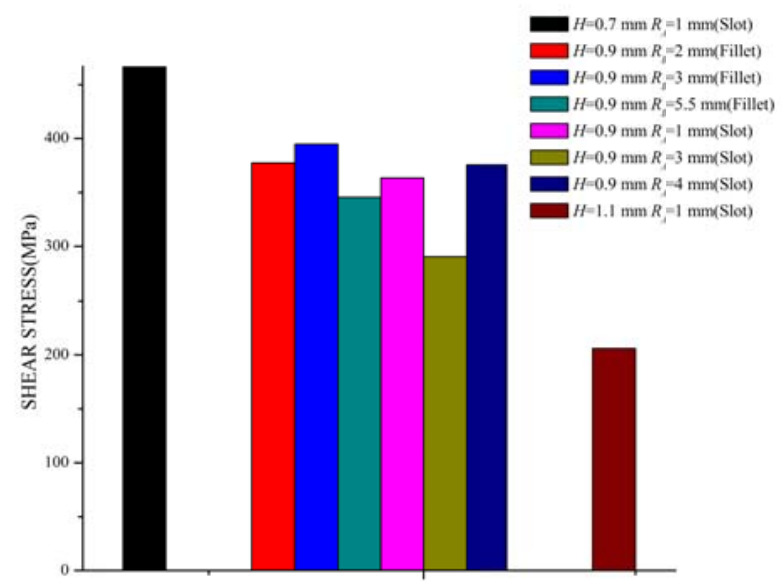

Fig. 11. Maximum shear stress of each cruciform geometry.

\section{Conclusions}

In this study, a numerical approach, based on the finite element method is presented to highlight the advantage of design idea of biaxial tensile cruciform specimen. Specimen unilateral thinned is processed easily. Based on the standard recommended by ISO/CD16842, the influence of the key dimensions of specimen on the strain distribution is discussed as following:

Firstly, thickness of central area can be decreased moderately to increase deformation, and the best value should be controlled by $40 \%$ to $50 \%$.

Secondly, concave fillet make stress-strain distribution lost its uniformity and Maximum shear stress appears in the fillet.

Finally, fillet increasing outwards to $2-7 \%$ of specimen width can reduce of maximum shear stress and strain distribution to be even. 


\section{References}

[1] Meng B, Wan M, Wu X, et al. Constitutive modeling for high-temperature tensile deformation behavior of pure molybdenum considering strain effects[J]. International Journal of Refractory Metals and Hard Materials, 2014, 45: 41-47.

[2] Bhattacharya R, Lan Y J, Wynne B P, et al. Constitutive equations of flow stress of magnesium AZ31 under dynamically recrystallizing conditions[J]. Journal of Materials Processing Technology, 2014, 214(7): 1408-1417.

[3] Shiratori E, Ikegami K. A new biaxial tensile testing machine with flat specimen[J]. Bulletin of the Tokyo Institute of Technology, 1967, 82: 105-118.

[4] Shiratori E, Ikegami K. Experimental study of the subsequent yield surface by using cross-shaped specimens[J]. Journal of the Mechanics and Physics of Solids, 1968, 16(6): 373-394.

[5] Kuwabara T. Advances in experiments on metal sheets and tubes in support of constitutive modeling and forming simulations[J]. International Journal of Plasticity, 2007, 23(3): 385-419.

[6] Makinde A, Thibodeau L, Neale K. Development of an apparatus for biaxial testing using cruciform specimens[J]. Experimental mechanics, 1992, 32(2): 138-144.

[7] Kuwabara T, Ikeda S, Kuroda K. Measurement and analysis of differential work hardening in cold-rolled steel sheet under biaxial tension[J]. Journal of Materials Processing Technology, 1998, 80-81: 517-523.

[8] Verma R K, Kumar A, Manikandan G, et al. Modelling anisotropic hardening of an ultra low carbon high strength steel using crystal plasticity[J]. Materials Science and Engineering: A, 2013, 559: 359-363.

[9] Hakoyama T, Kuwabara T. Forming Limit Analyses of Cold Rolled IF Steel Sheet Using Differential Work Hardening Model[J]. Procedia Engineering, 2014, 81: 1246-1251.

[10] Merklein M, Biasutti M. Development of a biaxial tensile machine for characterization of sheet metals[J]. Journal of Materials Processing Technology, 2013, 213(6): 939-946.

[11] Yu Y, Wan M, Wu X-D, et al. Design of a cruciform biaxial tensile specimen for limit strain analysis by FEM[J]. Journal of Materials Processing Technology, 2002, 123(1): 67-70.

[12] Leotoing L, Guines D. Investigations of the effect of strain path changes on forming limit curves using an in-plane biaxial tensile test[J]. International Journal of Mechanical Sciences, 2015, 99: 21-28.

[13] Hannon A, Tiernan P. A review of planar biaxial tensile test systems for sheet metal[J]. Journal of Materials Processing Technology, 2008, 198(1-3): 1-13. 